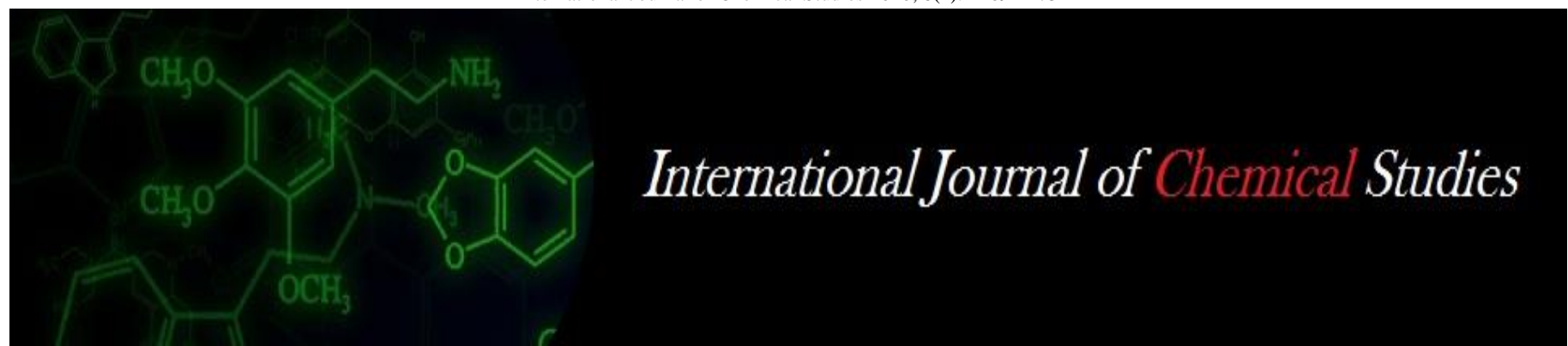

P-ISSN: 2349-8528

E-ISSN: 2321-4902

IJCS 2020; 8(1): 1269-1273

(C) 2020 IJCS

Received: 04-11-2019

Accepted: 06-12-2019

Ram Prasad Bebartta

Department of Food Technology

\& Management, NIFTEM,

Sonepat, Haryana, India

Komal Purushottam Katekhaye Department of Food Technology \& Management, NIFTEM, Sonepat, Haryana, India

Rameshwar Shivshankar Gajbharkar

Department of Food Technology \& Management, NIFTEM,

Sonepat, Haryana, India

Aishwarya Mishra

Department of Food Technology

\& Management, NIFTEM,

Sonepat, Haryana, India

Nihar Ranjan Sahoo

AICRP on PHET, Department

of Agricultural Processing \&

Food Engineering, OUAT,

Bhubaneswar, Odisha, India

Corresponding Author: Nihar Ranjan Sahoo AICRP on PHET, Department of Agricultural Processing \& Food Engineering, OUAT, Bhubaneswar, Odisha, India

\section{Development of edible packaging film from banana peels and effect of glycerol concentration on the film properties}

\author{
Ram Prasad Bebartta, Komal Purushottam Katekhaye, Rameshwar \\ Shivshankar Gajbharkar, Aishwarya Mishra and Nihar Ranjan Sahoo
}

DOI: $\underline{\text { https://doi.org/10.22271/chemi.2020.v8.i1r.8430 }}$

\begin{abstract}
Edible film from banana peel was developed with incorporation of varying levels of glycerol $(5,10,15$ and 20\%) as plasticizers. Different parameters including thickness of the edible film, moisture content of the film by hot air oven method, tearing strength, density, water absorption, solubility, water vapor transmission rate(WVTR) and color were studied. The study shows the best result at $10 \%$ glycerol concentrations.
\end{abstract}

Keywords: Edible film, banana peel, plasticizer, film properties

\section{Introduction}

Films are generally defined as stand-alone thin layers of materials. They usually consist of polymers, which provide mechanical strength to the films. The only difference between sheets and films is their thickness. Films can form pouches, bags, wraps, capsules or casings through further fabrication processes. The use of edible film as carrier of active substances has been suggested as a promising application of active food packaging (Cuq et al., 1995) ${ }^{[4]}$. Edible films are produced from edible biopolymers and food grade additives. The biopolymers include proteins, polysaccharides (carbohydrates and gums) or lipids etc. (Gennadios et al., 1997) [6]. Plasticizers and other food additives are added to biopolymers to modify the functionality of the film. For the resulting film to be edible, the film forming mechanism involved in fabrication should be an appropriate food process namely $\mathrm{pH}$ modification, salt addition, heating, enzymatic modification, drying, use of food grade solvents and addition of other food grade chemicals. Edible films enhance the quality of food products; protect them from physical, chemical and biological deteriorations (Kester and Fennema, 1986) ${ }^{[9]}$.

Banana (Musa sapientum) is a popular fruit consumed all over the world. Banana peel is the outer covering of the banana fruit. Once the peel is removed, the fruit can be eaten raw or cooked and the peel is generally discarded. Because of this removal of the banana peel, a significant amount of organic waste is generated. Banana peels (30\% of fruit weight) are usually discarded, causing pollution because of their susceptibility to microbial degradation (González-Montelongo et al 2010) ${ }^{[7]}$. Banana peels can be used as a feed material for animals and for manufacturing of several other biochemical products. Green banana peels contain about $15 \%$ starch. Banana peels have been presented as sources of pectin (Emaga et al 2008, Oliveira et al 2016) ${ }^{[5,10]}$ as well as cellulose (Oliveira et al 2016, Tibolla et al 2014) ${ }^{[10,13] \text {, }}$ which makes their proper exploitation interesting from the perspective of valorization of byproducts for non-food applications in a bio refinery context, transforming them into valueadded products, decreasing their negative environmental impacts, and enhancing their economic feasibility. Pectins, present in plant primary cell walls and middle lamellae, have a main backbone consisting of $\alpha$-1,4-linked galacturonic acids with variable degree of methoxylation (DM) of their carboxylic acid residues (Yapo et al 2007) ${ }^{[14]}$.

Edible packaging film using banana peel can be manufactured which, would serve many useful purposes. Some of them are, it is all natural and contain no toxic, allergic and non-digestible components. It provides structural stability and prevents mechanical damage during transportation, handling, and display. 
It has good adhesion to surface of food to be protected providing uniform coverage. It controls water migration both in and out of protected food to maintain desired moisture content. It provides semi-permeability to maintain internal equilibrium of gases involved in aerobic and anaerobic respiration, thus retarding senescence. It prevents loss or uptake of components that stabilize aroma, flavor, nutritional and organoleptic characteristics necessary for consumer acceptance while not adversely altering the taste or appearance. It also provides biochemical and microbial surface stability while protecting against contamination, pest infestation, microbe proliferation, and other types of decay. It helps in maintaining and enhancing aesthetics and sensory attributes (appearance, taste etc.) of the product. It can serve as carrier for desirable additives such as flavor, fragrance, coloring, nutrients and vitamins. Incorporation of antioxidants and antimicrobial agents can be limited to the surface through use of edible films, thus minimizing cost and intrusive taste. Last but not least it can be easily manufactured and economically viable (Pavlath and Orts, 2009) ${ }^{[11]}$. Due to the above advantages and to give a meaningful use of largely wasted peels of banana an attempt was made to make edible film from banana peel with a purpose to use it as a future of food packaging material. Also different physical and biochemical parameters have been studied in this research work. Pectins from other sources have been used for development of biodegradable films (Cabello et al 2015, Penhasi and Meidan 2014) ${ }^{[3,12]}$.

General nutritional composition of banana peel is given in Table 1 which shows it has got good amount of crude carbohydrates and crude fiber, which is ideal for film making process.

Table 1: Nutritional composition of banana peels (Anhwange, 2008) ${ }^{[1]}$

\begin{tabular}{|c|c|}
\hline Component & Amount in 100 g \\
\hline Protein & 0.90 \\
\hline Crude lipid & 1.70 \\
\hline Carbohydrate & 59.00 \\
\hline Crude fibre & 31.70 \\
\hline \multicolumn{2}{|c|}{ Minerals $\left(\mathrm{mg} \mathrm{g}^{-1}\right)$} \\
\hline Potassium & 78.10 \\
\hline Calcium & 19.20 \\
\hline Sodium & 24.30 \\
\hline Iron & 0.61 \\
\hline Manganese & 76.20 \\
\hline Bromine & 0.04 \\
\hline Rubium & 0.21 \\
\hline Strontium, & 0.03 \\
\hline Zirconium & 0.02 \\
\hline Niobium & 0.02 \\
\hline
\end{tabular}

\section{Materials and methods}

Fig. 1 gives the flow diagram of the banana peel manufacturing process.

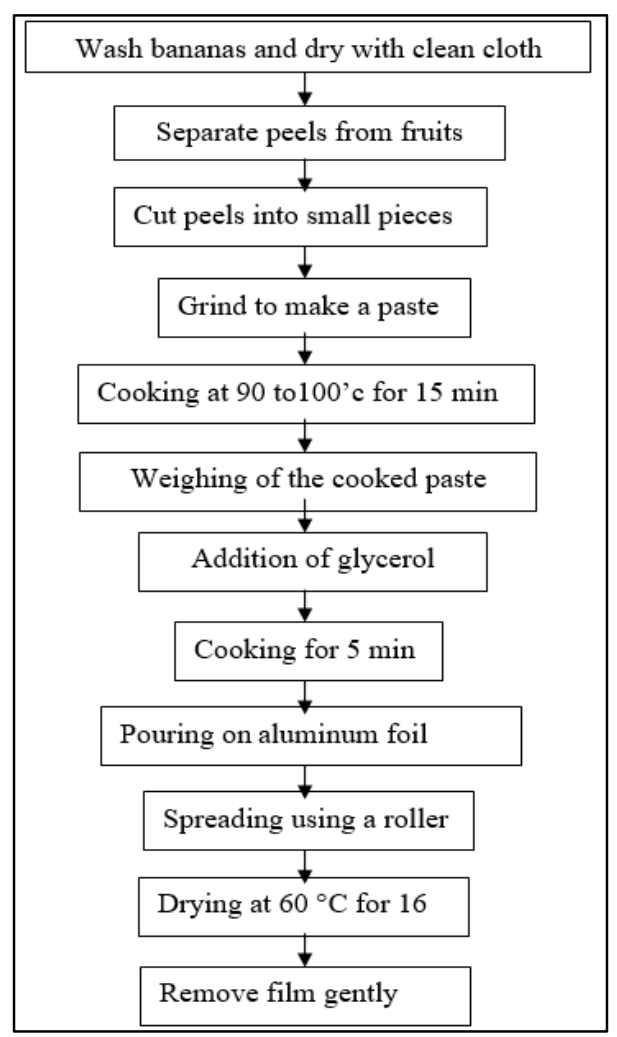

Fig 1: Banana peel film manufacturing process
Different properties of the developed films were studied, which includes moisture content, tearing strength, film density, film solubility in water, film swelling index and water vapour transmission rate using following standard methods.

\section{Determination of moisture content}

Higher the moisture content, more preservatives are required. Again excess moisture in mixes can cause clumping and the moisture content will continue to increase during storage. Also different features of the product, like texture, appearance or the stability varies with different amount of moisture in it. Thus the moisture content of the developed films was measured using standard hot air oven drying method.

\section{Determination of film thickness}

The sample thicknesses were determined with a micrometer to the nearest $0.01 \mathrm{~mm}$ at 6 random locations.

\section{Determination of film density}

Density of the developed films was determined using densimeter of make and model Mettler-Toledo (M) Sdn. Bhd. The immersing liquid used in this work was Xylene instead of distilled water to avoid water uptake by the hydrophilic film samples due to its lower density. In addition, the density of the liquid had to be less than the film to ensure that the film does not float. Hence, Xylene is much more suitable compared to water. The film sample was weighted $(\mathrm{m})$ before immersing it in the liquid. The amount of liquid displaced after immersing film into the liquid was recorded as volume 
(V). Density of the films is given by ratio of mass by volume and is given in $\mathrm{g} / \mathrm{cc}$.

\section{Determination of tearing strength}

Tearing strength is an important test for all films as well as paper. Tearing strength of the film consists of measuring the work done when the sample of film is torn through a specified distance. The work is done partly in rupturing the film along the line of the tear and partly in bending the paper as it is being torn. Tear strength (reported in $\mathrm{gm}$ ) is the force necessary to continue tearing of a sample after a nick has been made. The total work done is used along with the length of the tear and the number of sheets torn together in the tear, to calculate a single force which, for the purpose of this method is described as the force required to continue the tearing of a single sheet of paper. This force expressed in grams weight is defined as the tearing resistance of the paper is attached is mounted on the pendulum coaxially, the position of the pointer relative to the pendulum can be read from a circumferential scale carried on the pendulum.

Tearing Strength $=\frac{\text { Scale Reading X } 16}{\text { Number of Sheets }}$

$$
\text { Tear Factor }=\frac{\text { Tearing strength } \times 100}{\text { GSM }}
$$

\section{Tear Index $=$ Tear factor $\mathbf{x} \mathbf{0 . 0 9 8}$}

\section{Determination of film solubility}

For determining film solubility in water, three samples of 2 $\mathrm{cm}$ diameter were obtained from each film and dried in an oven at $105{ }^{\circ} \mathrm{C}$ for $24 \mathrm{~h}$. The samples were weighed to determine the initial dry matter of each film $\left(\mathrm{W}_{\mathrm{i}}\right)$. Then each sample was immersed in $30 \mathrm{~mL}$ of distilled water and kept at $23 \pm 2{ }^{\circ} \mathrm{C}$ for $24 \mathrm{~h}$. The sealed beaker was stirred periodically. The insoluble portion of film sample were removed from soluble matters in distilled water and dried in an oven at 105 ${ }^{\circ} \mathrm{C}$ for $24 \mathrm{~h}$. The oven dried samples were reweighed to know the weight of the solubilized dry matter $\left(\mathrm{W}_{\mathrm{o}}\right)$. Water solubility of each film was determined by

Solubility $(\%)=\frac{W i-W o}{W i} \times 100$

\section{Determination of water sorption capacity}

Water sorption capacity of each film was studied by immersing a known mass of film sample into distilled water at room temperature $\left(23 \pm 2{ }^{\circ} \mathrm{C}\right)$. The Film was periodically removed from the distilled water and reweighed until constant film mass was attained. The test was performed in triplicate. The water uptake was determined using following Eq.

Swelling Index $(\%)=\frac{\text { Mswollen }- \text { Mdry }}{\text { Mdry }} \times \mathbf{1 0 0}$

Where $M_{\text {Dry }}$ and $M_{\text {Swollen }}$ represents initial and swollen mass of film sample, respectively. This method was adapted from (González, 2010) ${ }^{[7]}$.

\section{Determination of water vapor transmission rate}

WVTR (Water Vapor Transmission Rate) measures the transmission of water vapor through a material. WVTR is measured in either grams $/ 100 \mathrm{in}^{2} / 24$ hours or grams $/ \mathrm{m}^{2}$ during 24 hours. WVTR is the standard measurement by which films are compared for their ability to resist moisture transmission. Lower values indicate better moisture protection. Only values reported at the same temperature and humidity can be compared, because transmission rates are affected by both of these parameters. Testing material for WVTR properties requires that the test specimen be held such that it separates two sides of a test chamber. The wet side of the specimen is exposed to a high relative humidity atmosphere, while the dry side is subjected to a zero relative humidity atmosphere. Infrared sensors on the dry side detect the amount of water vapor present. Testing is complete when the concentration of water vapor in the dry side atmosphere is constant. Under a certain test temperature, a constant humidity difference is generated between two sides of the test specimen; the water vapor permeates through the specimen and into the dry side. By measuring the weight changes of the best test dish in different time, water vapor transmission rate and other parameters are obtained.

\section{Determination of colour difference}

Colour difference was measured using the following formula

$\Delta \mathrm{E}=$ square root of $(\Delta \mathrm{L})^{2}+(\Delta \mathrm{a})^{2}+(\Delta \mathrm{b})^{2}$

Where ' $L$ ' represents brightness, ' $a$ ' represents the difference between green and red, while b represents the difference between blue and yellow colour in comparison with the initial values.

\section{Results}

Banana peel based edible films without adding plasticizer (glycerol) are brittle with many visible cracks and not easily peeled from the casting surface. Introduction of glycerol as plasticizer helped to overcome brittleness and enhanced the flexibility and the peelability of banana films from casted surface. Effect of different levels of plasticizers on various physical and chemical properties of developed casted film is given below.

Effect of glycerol concentration on moisture content (\%) Moisture content of the films increased from 6.4 to $8.3 \%$ as concentration of glycerol increases from value 10 to $20 \%$ (Fig. 2). The hydroxyl groups in glycerol have strong affinity with water molecules; enabling glycerol containing film to easily retain in water within their matrix and form hydrogen bonds. Hence, glycerol acts as water holding agent. Similar investigations reported that the moisture content of hydrocolloid films increases by adding more plasticizer

Effect of glycerol concentration on film thickness ( $\mathrm{mm}$ )

Fig. 2 shows the effect of glycerol concentration on film thickness. As glycerol concentration increases from 10 to 20 $\%$, thickness of film increases from $0.1 \mathrm{~mm}$ to $0.5 \mathrm{~mm}$. This may be attributed to the role of plasticizers in disrupting and restructuring of intermolecular polymer chain network, creating more free volumes which translate into thicker film thickness. Similar effect of plasticizer concentration on film thickness was reported by Jouki et al. (2013) ${ }^{[8]}$. 

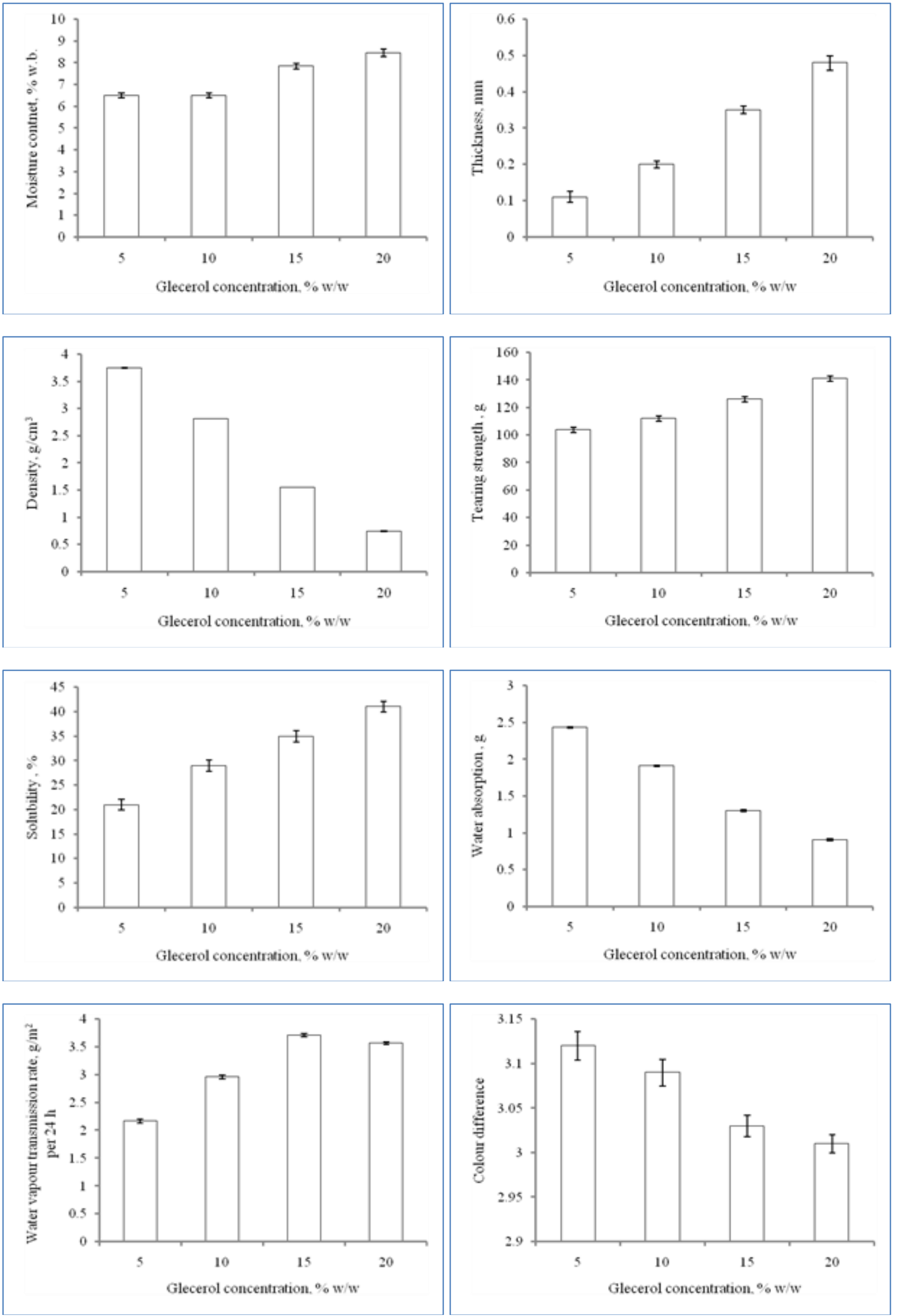

Fig 2: Film properties as functions of glycerol concentration on edible banana packaging film 


\section{Effect of glycerol concentration on film density $\left(\mathrm{g} / \mathrm{cm}^{3}\right)$}

Addition of plasticizer lowers the density of film as increasing concentration of plasticizer from 10 to 20\%, slight decreasing in density of film from 2.812 to $0.743 \mathrm{~g} / \mathrm{cm}^{3}$ (Fig. 2). This is due to difference in molecular weight in terms of added concentration of glycerol.

\section{Effect of concentration of glycerol on tearing strength of edible film}

As there is increase the concentration of glycerol the tearing strength of the film tends to increase from an initial value of $104 \mathrm{~g}$ with $5 \%$ glycerol to $141 \mathrm{~g}$ with $20 \%$ glycerol. This is due to the binding properties of plasticizer (Fig. 2).

\section{Effect of glycerol concentration on solubility (\%) of edible film}

Solubility of edible film increases with increase in concentration of plasticizer as shown in (Fig. 2). Due to hydrophilic nature of the plasticizer, increase in concentration will weaken the interaction between polymer molecule chains increasing the free space volumes between the chains. This in turn promotes water diffusion into the film matrix and consequently increasing the solubility of the edible film.

\section{Effect of glycerol concentration on the water absorption (g) of edible film and its swelling index}

Films were emerged in water to verify the effect of plasticizer type and concentration on the hydrophilic nature of starch based films. Water diffuses into the network chains of the films, thus, causing the film to swell. The swelling of all the films were rapid during the initial $6 \mathrm{~h}$ and later followed by slower swelling rate until they reach equilibrium. This phenomenon may be due to the abundant active hydroxyl groups of films which were vacant at the initial stage of absorption process. However, the active sites were gradually saturated until they could no longer accommodate any water molecule. This point is referred to as equilibrium state. The addition of plasticizers effectively decreased the swelling and water retaining capacity of edible film.

\section{Effect of glycerol concentration on colour difference}

There was gradual decrease in colour difference values with increase in plasticizer in the developed films. The value decreasd from 3.12 with $5 \%$ glycerol to 3.01 with $20 \%$ glycerol.

\section{Discussion}

The result shows that concentration of plasticizer influences film thickness, density, moisture content, solubility, swelling capacity and water absorption. Gradually increasing the concentration from 10 to $20 \%$ increases the film thickness, moisture content and solubility but decreases the density and water absorption capacity of banana films. Effect of concentration of plasticizer shows negligible effect on water vapor permeability and color difference. Based on the effect of different concentration of plasticizer on the properties of banana films, $10 \%$ concentration of plasticizer is found to be optimum for developing food packaging film from banana peel.

\section{Conclusion}

Concerns about environmental impacts from food packaging waste have motivated development of biodegradable materials, mostly from renewable sources. Banana peel based is successfully developed as material for the preparation of film by combining with plasticizer. Banana peel based edible films without adding plasticizer(glycerol) are brittle with many visible cracks and not easily peeled from the surface. Hence, the introduction of glycerol as plasticizer helped to overcome brittleness and, enhance flexibility and peelability of banana films. The result shows that concentration of plasticizer influences film thickness, density, moisture content, solubility, swelling capacity and water absorption. Gradually increasing the concentration from 10 to $20 \%$ increases the film thickness, moisture content and solubility but decreases the density and water absorption capacity of banana films. Effect of concentration of plasticizer shows negligible effect on water vapor permeability and color difference. Based on the effect of different concentration of plasticizer on the properties of banana films, $10 \%$ concentration of plasticizer is best for developing food packaging film from banana peel.

\section{References}

1. Anhwange BA. Chemical Composition of Musa sapientum (Banana) Peels. Journal of Food Technology. 2008; 6(6):263-266

2. Bio nano composites for Packaging Applications edited by Mohammad Jawaid, Sarat Kumar Swain, published by Springers, 2018.

3. Cabello SDP, Takara EA, Marchese J, Ochoa NA. Influence of plasticizers in pectin films: microstructural changes, Mater. Chem. Phys. 2015; 162:491-497.

4. Cuq B, Aymard C, Cuq J, Guilbert S. Edible packaging films based on fish myofibrillar proteins: formation and functional properties. J Food Sci. 1995; 60:1369-1374.

5. Emaga TH, Robert C, Ronkart SN, Wathelet B, Paquot M. Dietary fibre components and pectin chemical features of peels during ripening in banana and plantain varieties, Bioresour. Technol. 2008; 99:4346-4354.

6. Gennadios et al. Plastic Films in Food Packaging: Materials, Technology and Applications edited by Sina Ebnesajjad, 1997.

7. González-Montelongo R, Lobo MG, González M. Antioxidant activity in banana peel extracts: testing extraction conditions and related bioactive compounds, Food Chem. 2010; 119:1030-1039.

8. Jouki M, Khazaei N, Ghasemlou M, HadiNezhad M. Effect of glycerol concentration on edible film production from cress seed carbohydrate gum. Carbohydrate Polym. 2013; 96:39-46.

9. Kester, Fennema. Innovations in Food Packaging edited by Jung H. Han, 1986.

10. Oliveira TIS, Rosa MF, Cavalcante FL, Pereira PHF, Moates GK et al. Optimization of pectin extraction from banana peels with citric acid by using response surface methodology, Food Chem. 2016; 198:113-118.

11. Pavlath, Orts. Edible Films and Coatings for Food Applications edited by Milda E. Embuscado, Kerry C. Huber, 2009.

12. Penhasi A, Meidan VM. Preparation and characterization of in situ ionic cross-linked pectin films: unique biodegradable polymers, Carbohydrate. Polym. 2014; 102:254-260.

13. Tibolla H, Pelissari FM, Menegalli FC. Cellulose nanofibers produced from banana peel by chemical and enzymatic treatment, LWT - Food Sci. Technol. 2014; 59:1311-1318.

14. Yapo BM, Robert C, Etienne I, Wathelet B, Paquot M. Effect of extraction conditions on the yield: purity and surface properties of sugar beet pulp pectin extracts, Food Chem. 2007; 100:1356-1364. 